BMJ Open

Diabetes

Research

\& Care

\title{
Pleiotropic effects of sitagliptin versus voglibose in patients with type 2 diabetes inadequately controlled via diet and/or a single oral antihyperglycemic agent: a multicenter, randomized trial
}

Yukiko Matsushima,,${ }^{1,2,3}$ Yumie Takeshita, ${ }^{1,2,3}$ Yuki Kita, ${ }^{1,3}$ Toshiki Otoda, ${ }^{1,3}$ Ken-ichiro Kato, ${ }^{1,3}$ Hitomi Toyama-Wakakuri, ${ }^{1,3}$ Hiroshi Akahori, ${ }^{3}$ Akiko Shimizu, ${ }^{3}$ Erika Hamaguchi, ${ }^{3}$ Yasuyuki Nishimura, ${ }^{3}$ Takehiro Kanamori, ${ }^{1,3}$ Shuichi Kaneko, ${ }^{2}$ Toshinari Takamura ${ }^{1,2,3}$

To cite: Matsushima $Y$, Takeshita Y, Kita Y, et al. Pleiotropic effects of sitagliptin versus voglibose in patients with type 2 diabetes inadequately controlled via diet and/or a single oral antihyperglycemic agent: a multicenter, randomized trial. BMJ Open Diabetes Research and Care 2016;4:e000190. doi:10.1136/bmjdrc-2015000190

- Additional material is available. To view please visit the journal (http://dx.doi.org/ 10.1136/bmjdrc-2015000190).

YM, YT and TT contributed equally.

Received 24 December 2015 Revised 4 February 2016 Accepted 15 February 2016

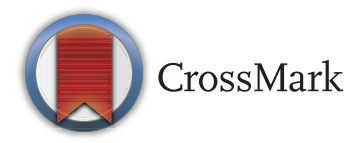

For numbered affiliations see end of article.

Correspondence to Professor Toshinari Takamura;

ttakamura@m-kanazawa.jp

\section{ABSTRACT}

Purpose: A step-up strategy for diet therapy and/or single oral antihyperglycemic agent $(\mathrm{OHA})$ regimens has not yet been established. The aim of this study was to evaluate hemoglobin $\mathrm{A} 1 \mathrm{c}(\mathrm{HbA} 1 \mathrm{c})$ as a primary end point, and the pleiotropic effects on metabolic and cardiovascular parameters as secondary end points, of sitagliptin versus voglibose in patients with type 2 diabetes with inadequate glycemic control while on diet therapy and/or treatment with a single OHA.

Methods: In this multicenter, randomized, open-label, parallel-group trial, a total of 260 patients with inadequately controlled type 2 diabetes ( $\mathrm{HbA} 1 \mathrm{c}$ levels $>6.9 \%$ ) were randomly assigned to receive either sitagliptin (50 mg, once daily) or voglibose $(0.6 \mathrm{mg}$, thrice daily) for 12 weeks. The primary end point was $\mathrm{HbA1c}$ levels.

Results: Patients receiving sitagliptin showed a significantly greater decrease in $\mathrm{HbA} 1 \mathrm{c}$ levels $(-0.78$ $\pm 0.69 \%$ ) compared with those receiving voglibose $(-0.30 \pm 0.78 \%)$. Sitagliptin treatment also lowered serum alkaline phosphatase levels and increased serum creatinine, uric acid, cystatin- $C$ and homeostasis model assessment- $\beta$ values. Voglibose increased low-density lipoprotein-cholesterol levels and altered serum levels of several fatty acids, and increased $\Delta-5$ desaturase activity. Both drugs increased serum adiponectin. The incidence of adverse events (AEs) was significantly lower in the sitagliptin group, due to the decreased incidence of gastrointestinal AEs.

\section{Conclusions: Sitagliptin shows superior}

antihyperglycemic effects compared with voglibose as a first-line or second-line therapy. However, both agents possess unique pleiotropic effects that lead to reduced cardiovascular risk in Japanese people with type 2 diabetes.

Trial registration number: UMIN 000003503.

\section{Key messages}

- This study directly compared a hemoglobin A1c and the pleiotropic effects of sitagliptin with voglibose added to concurrent treatment in Japanese patients with type 2 diabetes who could not achieve adequate glycemic control through diet therapy or a single OHA. Compared to voglibose, sitagliptin was superior to voglibose in lowering $\mathrm{Hb} 1 \mathrm{Ac}$ levels in monotherapy and in combination therapy.

- Sitagliptin, but not voglibose, might impair renal function. Sitagliptin significantly increased serum Cre and cys-C decreased estimated glomerular filtration rate average.

- Sitagliptin significantly decreased polyunsaturated fatty acids, especially $\omega 6$ fatty acids, whereas voglibose altered serum levels of many kinds of fatty acids. Voglibose, but not sitagliptin, increased $\Delta-5$ desaturase activity. Both sitagliptin and voglibose exert significant unique pleiotropic effects on surrogate cardiovascular risks.

\section{INTRODUCTION}

Recent large-scale clinical trials have suggested that intensive antidiabetic therapies that cause unnecessary hyperinsulinemia do not achieve satisfactory cardiovascular outcomes in people with type 2 diabetes, as they may lead to hypoglycemia and weight gain. ${ }^{1}$ To avoid these problems, incretin-based agents that do not provoke unnecessary hyperinsulinemia have been developed, and are generally used as second- or third-line therapies, in addition to metformin, in Western countries. ${ }^{2}$ However, to date, limited 
clinical evidence is available regarding incretin-based agents as first-line or second-line antihyperglycemic therapies.

Sitagliptin is an inhibitor of dipeptidyl peptidase-4 (DPP-4), which subsequently prevents enzymatic inactivation of endogenous glucagon-like peptide-1 (GLP-1) ${ }^{3}$ and thus improves glycemic control in type 2 diabetes. Sitagliptin has proven effective both as a monotherapy and in combination with other oral antihyperglycemic agents, ${ }^{45}$ although it is thought to be more effective in Asian patients than in Caucasian patients. ${ }^{6}$ However, the majority of studies on sitagliptin monotherapy and combination therapy are based on non-Japanese patients, and its pleiotropic effects have not been investigated extensively, especially in Japanese patients.

Voglibose is an $\alpha$-glucosidase inhibitor widely used to improve postprandial hyperglycemia. The antidiabetic actions of voglibose may be mediated, at least in part, by endogenous incretins because an $\alpha$-glucosidase inhibitor may increase GLP-1 levels both by inhibiting DPP-4 activity $^{7}$ and by delaying intestinal absorption of a meal. ${ }^{8}$ However, the differences between sitagliptin and voglibose are unknown from the perspective of understanding pleiotropic effects.

The aim of this study was to evaluate hemoglobin A1c (HbAlc) as a primary end point, and the pleiotropic effects on metabolic and cardiovascular parameters as secondary end points, of sitagliptin versus voglibose in Japanese patients with type 2 diabetes who were unable to achieve adequate glycemic control via diet therapy and/or OHA monotherapy. Notably, dynamic randomization was used to adjust for demographic differences between the groups.

\section{RESEARCH DESIGN AND METHODS Overview}

This was a randomized, parallel-group study conducted on Japanese patients. The study was designed in accordance with the principles stated in the Declaration of Helsinki, and the protocol was reviewed and approved by the appropriate institutional review board for each study site. All patients provided written informed consent before participation.

A total of 260 type 2 diabetes patients who were unable to achieve adequate glycemic control via diet therapy and/ or OHA monotherapy were recruited from 19 centers in Japan between May 2011 and August 2012. Type 2 diabetes was diagnosed according to WHO criteria, based on a $2 \mathrm{~h}$ plasma glucose value of $>11.1 \mathrm{mmol} / \mathrm{L} .^{9}$ Inadequate disease control was defined as having a Hb1Ac level $>6.9 \%$. The trial was registered with the University Hospital Medical Information Network (UMIN) Clinical Trials Registry (registration number UMIN000003503).

\section{Patient eligibility}

Participants were eligible if they were at least 20 years old, had type 2 diabetes mellitus, poorly controlled diabetes (HbAlc levels $>6.9 \%$ within 12 weeks before screening), and had been treated with diet therapy and/ or a single OHA, such as sulfonylurea (SU), biguanide (BG) or thiazolidinedione (TZD) class drugs, for 12 weeks or longer.

Exclusion criteria were: (1) hypersensitivity or a contraindication to sitagliptin or voglibose; (2) history of type 1 diabetes; (3) history of ketoacidosis; (4) having experienced symptoms of hypoglycemia; (5) treatment with sitagliptin or voglibose within 12 weeks before screening; (6) treatment with insulin within 12 weeks before screening; (7) concomitant corticosteroid therapy; (8) poorly controlled or unstable diabetes (the state with ketoacidosis or with an increase in HbAlc $>3 \%$ in the 12 weeks before screening); (9) alanine aminotransferase and/or aspartate aminotransferase levels more than 2.5-fold the upper limit of normal; (10) poorly controlled hypertension or systolic blood pressure $>160 \mathrm{~mm} \mathrm{Hg}$ or diastolic blood pressure $>100 \mathrm{~mm} \mathrm{Hg}$; (11) presence of a severe health problem not suitable for the study; (12) pregnancy or breastfeeding; or (13) inability to participate in the study due to psychiatric or psychosocial status as assessed by the investigators.

\section{Efficacy endpoints}

A computer-generated randomization sequence was used to assign participants in a 1:1 ratio to either the sitagliptin or voglibose treatment group. Dynamic randomization was used to adjust for demographic differences (age, previous treatment for type 2 diabetes and HbAlc level) between the groups. In this activecomparator, parallel-group trial, eligible patients received either sitagliptin or voglibose in addition to their previous treatment for 12 weeks. Sitagliptin (Merck \& Co, Inc, New Jersey, USA) was initiated and maintained at $50 \mathrm{mg}$ once daily. Voglibose (Takeda Pharmaceutical Company Limited, Osaka, Japan) was initiated and maintained at $0.6 \mathrm{mg}(0.2 \mathrm{mg}$ with each meal). Other medications were unchanged during the study period.

The primary efficacy end point was the change in Hb1Ac levels from baseline over the 12-week period. Secondary end points recorded at baseline and week 12 included: fasting plasma glucose (FPG); serum creatinine (Cre); uric acid; alkaline phosphatase (ALP), bone alkaline phosphatase (BAP), cystatin-C (cys-C), 1,5-anhydroglucitol (1,5-AG), fasting serum insulin (IRI), fasting serum proinsulin, fasting C-peptide immunoreactivity (CPR), factors related to fasting lipid profile (including small dense low-density lipoprotein, lowdensity lipoprotein-cholesterol, adiponectin, tumour necrosis factor $\alpha$ (TNF- $\alpha)$ and leptin); blood pressure; and physical measures (waist circumference, body mass index (BMI)). The estimated glomerular filtration rates based on serum Cre (eGFRcreat) and serum cys-C (eGFRcys), and the average estimated glomerular filtration rate (eGFRaverage), were calculated using the following formulas: eGFRcreat $=194 \times \mathrm{Cr}^{-1.094} \times \mathrm{Age}^{-0.287}$ 
(males) or $194 \times \mathrm{Cr}^{-1.094} \times \mathrm{Age}^{-0.287} \times 0.739 \quad$ (females); eGFRcys $=\left(104 \times\right.$ Cystatin $\left.\mathrm{C}^{-1.019} \times 0.996^{\text {age }}\right)-8 \quad$ (males) or $\left(104 \times\right.$ Cystatin $\left.\quad \mathrm{C}^{-1.019} \times 0.996^{\text {age }} \times 0.929\right)-8 \quad$ (females); eGFRaverage $=(($ eGFRcreat+eGFRcys $) / 2) .{ }^{10} 11$ The homeostasis model assessment of insulin resistance (HOMA-IR) was used as a conventional index for insulin resistance and was calculated as $(\mathrm{IRI}(\mathrm{U} / \mathrm{mL}) \times \mathrm{FPG}(\mathrm{mmol} / \mathrm{L})) / 22.5) .{ }^{12}$ To assess basic insulin secretion by $\beta$ cells, CPR index (CPI), homeostasis model assessment- $\beta$ (HOMA- $\beta$ ), secretory unit of islet in transplantation index (SUIT index) and quantitative insulin sensitivity check index (QUICKI), were calculated as follows: $\mathrm{CPI}=$ $(100 \times$ fasting CPR $(\mathrm{ng} / \mathrm{mL})) / \quad$ FPG $\quad(\mathrm{mg} / \mathrm{dL})),{ }^{13}$ HOMA- $\beta=($ IRI $\quad($ IU $/ \mathrm{L}) \times 20 /(\mathrm{FPG}(\mathrm{mg} / \mathrm{dL})-63)),{ }^{14}$ SUIT index $=(1500 \times \mathrm{CPR} \quad(\mathrm{ng} / \mathrm{mL}) /(\mathrm{FPG} \quad(\mathrm{mg} / \mathrm{dL})$ $-63))^{15}$ and QUICKI $=(1 /(\log \operatorname{IRI}(\mathrm{IU} / \mathrm{L})+\log \quad \mathrm{FPG}$ $(\mathrm{mg} / \mathrm{dL}))^{16}$

Serum fatty acid levels were measured as a secondary outcome. A serum sample (approximately $0.2 \mathrm{~mL}$ ) and $2 \mathrm{~mL}$ of a chloroform-methanol solution (2:1) were placed in a Pyrex centrifuge tube, homogenized with a Polytron homogenizer (PCU-2-110; KINEMATICA $\mathrm{GmbH}$, Switzerland) and centrifuged at $3000 \mathrm{rpm}$ for $10 \mathrm{~min}$. An aliquot of the chloroform-methanol extract was transferred to another Pyrex tube and dried under a stream of nitrogen gas. The dried sample was dissolved in $100 \mu \mathrm{L}$ of $0.4 \mathrm{M}$ potassium methoxide methanol/14\% boron trifluoride-methanol solution, and the fatty acid concentrations were measured at SRL Inc (Tokyo, Japan), using a gas chromatograph (Shimizu GC 17A, Kyoto, Japan). Desaturase activities were estimated as follows: $\Delta-5$ desaturase, C20:4 $06 / \mathrm{C} 20: 3 \omega 6 ; \Delta-6$ desaturase, $18: 3 \omega-6 / 18: 2 \omega-6 .^{17}$

Medication adherence and adverse events were monitored throughout the study, and were rated by investigators for intensity and relationship to study drug.

\section{Statistical analysis}

The sample size required to detect a $-0.6 \%$ change in HbA1c levels in the sitagliptin group, and a $-0.4 \%$ change in the voglibose group, with a power of $80 \%$ $(\alpha=0.05$, one-tailed; $\beta=0.20)$ and standardized effect size of 0.6 , was 112 participants in each group. Taking into account a dropout rate of $15 \%$, we aimed to recruit 260 participants. All analyses used the full analysis set, which included all patients who received at least one dose of study drug and for whom data were available at baseline and from at least one postrandomization time point. Missing data were replaced by the last observed value of each variable in this analysis. Data were expressed as the mean \pm SD. The Statistical Package for the Social Sciences (SPSS) V.22.0 (SPSS Inc, Chicago, Illinois, USA) was used for the statistical analyses. Parameters were analyzed using the Wilcoxon signed-rank test in the internal group comparison, the $\chi^{2}$ test or the Mann-Whitney $U$-test, or the Kruskal-Wallis test, in the intergroup comparison. Associations between variables were assessed using Spearman's rank correlation coefficient. Multiple regression analysis was carried out to determine independent factors for changes in $\mathrm{HbA1c}$ by sitagliptin or voglibose. $p$ Values $<0.05$ were considered statistically significant.

\section{RESULTS}

\section{Patient characteristics}

A total of 260 patients were screened and randomly assigned to either the sitagliptin or voglibose regimen, and 241 participants (mean age, 63.2 \pm 12.7 years; mean BMI, $25.0 \pm 4.5 \mathrm{~kg} / \mathrm{m}^{2}$ ) were enrolled in this study (table 1 ). Nineteen patients were removed after randomisation before the intervention because they withdrew consent $(n=17)$ or did not meet inclusion criteria $(n=2$; see online supplementary figure S1). No participants took EPA or docosahexaenoic acid (DHA) before or during the study and other subject medications remained unchanged during the study period. One hundred and sixteen patients received diet therapy, 61 patients received SU, 57 patients received $\mathrm{BG}$ and seven patients received TZD. FPG and HbA1c levels were $154.7 \pm 35.1 \mathrm{mg} / \mathrm{dL}$ and 7.9 $\pm 0.9 \%$, respectively. Baseline demographics and disease characteristics of the two groups did not differ significantly (table 1). The serum TNF- $\alpha$ levels at baseline included two outliers in the sitagliptin group. The median was similar in the two groups (Sitagliptin versus Voglibose, 1.20 vs 1.10 $(\mathrm{pg} / \mathrm{mL}))$ and there was no significant difference in the Mann-Whitney $U$ test $(\mathrm{p}=0.166)$.

\section{Clinical outcomes}

Compared to baseline, FPG and HbA1c levels decreased significantly in both groups at the end of the study (table 2). Sitagliptin was superior to voglibose in lowering HbA1c levels $(-0.78 \pm 0.69$ vs $-0.30 \pm 0.78 \%$, respectively) and FPG concentrations $(-16.2 \pm 26.4$ vs -4.4 $\pm 38.7 \mathrm{mg} / \mathrm{dL}$, respectively) relative to baseline. There was no significant difference of medication adherence between the groups (table 1 ). In addition, in the stratified analysis on good $(\geq 80 \%)$ and poor $(<80 \%)$ adherence, adherence rate did not affect these results (see online supplementary table S1).

Both agents significantly increased 1,5-AG concentrations, but voglibose was superior to sitagliptin in this regard. Sitagliptin, but not voglibose, increased indices for insulin secretion such as HOMA- $\beta$, SUIT and CPI. Both agents lowered proinsulin levels and both agents exerted marked effects on the insulin sensitivity index, QUICKI.

Sitagliptin significantly reduced the counts of lymphocytes $(p=0.007)$ and significantly increased the counts of neutrophils $(p=0.008)$ at week 12 , whereas voglibose had no effect on them (table 2). Sitagliptin significantly lowered ALP levels from $236 \pm 71 \mathrm{IU} / \mathrm{L}$ at baseline to 226 $\pm 76 \mathrm{IU} / \mathrm{L}$ at week $12(\mathrm{p}=0.000)$ without changing bone alkaline phosphatase (BAP), whereas voglibose had no effect on ALP levels. Both agents were almost neutral in their effects on liver enzymes, except that voglibose 
Table 1 Characteristic of the study participants

\begin{tabular}{|c|c|c|c|c|}
\hline & All $(n=241)$ & Sitagliptin $(n=120)$ & Voglibose $(n=121)$ & p Value \\
\hline Male/Female & $143 / 98$ & $72 / 48$ & $71 / 50$ & 0.603 \\
\hline Age (years) & $63.2 \pm 12.7$ & $63.2 \pm 13.8$ & $63.2 \pm 11.6$ & 0.699 \\
\hline Medication adherence rate $(\geq 80 \% /<80 \%)$ & $193 / 48$ & $99 / 21$ & $94 / 27$ & 0.420 \\
\hline Combination therapy (Diet/SU/BG/TZD) & $116 / 61 / 57 / 7$ & $59 / 29 / 29 / 3$ & $57 / 32 / 28 / 4$ & 0.953 \\
\hline Body weight $(\mathrm{kg})$ & $64.8 \pm 14.4$ & $63.8 \pm 13.6$ & $65.8 \pm 15.1$ & 0.515 \\
\hline BMI $\left(\mathrm{kg} / \mathrm{m}^{2}\right)$ & $25.0 \pm 4.5$ & $25.0 \pm 4.5$ & $25.1 \pm 4.5$ & 0.984 \\
\hline Waist circumference (cm) & $89.9 \pm 11.1$ & $88.7 \pm 10.5$ & $91.0 \pm 11.7$ & 0.162 \\
\hline Systolic BP (mm Hg) & $130.8 \pm 17.7$ & $130.0 \pm 16.8$ & $131.6 \pm 18.5$ & 0.413 \\
\hline $\mathrm{FPG}(\mathrm{mg} / \mathrm{dL})$ & $154.7 \pm 35.1$ & $156.3 \pm 35.1$ & $153.2 \pm 35.2$ & 0.347 \\
\hline $\mathrm{HbA} 1 \mathrm{c}(\%)$ & $7.9 \pm 0.9$ & $7.9 \pm 1.0$ & $7.8 \pm 0.8$ & 0.935 \\
\hline $1.5 \mathrm{AG}(\mu \mathrm{g} / \mathrm{mL})$ & $6.9 \pm 4.8$ & $6.5 \pm 4.2$ & $7.4 \pm 5.3$ & 0.429 \\
\hline BUN (mg/dL) & $15.1 \pm 4.5$ & $14.9 \pm 4.1$ & $15.2 \pm 4.9$ & 0.886 \\
\hline $\mathrm{s}-\mathrm{Cre}(\mathrm{mg} / \mathrm{dL})$ & $0.72 \pm 0.23$ & $0.70 \pm 0.19$ & $0.74 \pm 0.27$ & 0.870 \\
\hline AST (IU/L) & $26 \pm 14$ & $26 \pm 13$ & $26 \pm 16$ & 0.823 \\
\hline ALT (IU/L) & $31 \pm 25$ & $32 \pm 25$ & $30 \pm 25$ & 0.522 \\
\hline$\gamma$-GTP (IU/L) & $46 \pm 53$ & $44 \pm 49$ & $49 \pm 57$ & 0.072 \\
\hline TC (mg/dL) & $188.4 \pm 33.0$ & $185.1 \pm 33.4$ & $191.6 . \pm 32.4$ & 0.130 \\
\hline $\mathrm{TG}(\mathrm{mg} / \mathrm{dL})$ & $140.1 \pm 93.6$ & $136.0 \pm 83.1$ & $144.2 \pm 103.1$ & 0.899 \\
\hline HDL-C (mg/dL) & $53.8 \pm 16.7$ & $52.7 \pm 15.4$ & $54.9 \pm 18.0$ & 0.250 \\
\hline LDL-C (mg/dL) & $106.2 \pm 28.1$ & $105.0 \pm 29.6$ & $107.5 \pm 26.5$ & 0.234 \\
\hline
\end{tabular}

Data are expressed as means \pm SD. $p$ Value for the intergroup comparison.

AG, anhydroglucitol; ALT, alanine aminotransferase; AST, aspartate aminotransferase; BG, biguanide; BMI, body mass index; BP, blood pressure; BUN, blood urea nitrogen; FPG, fasting plasma glucose; HbA1c, hemoglobin A1c; HDL-c, low-density lipoprotein cholesterol; LDL-C, low-density lipoprotein-cholesterol; s-Cre, serum creatinine; SU, sulfonylurea; TC, total cholesterol; TG, triglyceride; TZD, thiazolidinedione; $\gamma$-GTP, $\gamma$-glutamyl transpeptidase.

treatment decreased $\gamma$-GTP levels from $49 \pm 57 \mathrm{IU} / \mathrm{L}$ at baseline to $47 \pm 51 \mathrm{IU} / \mathrm{L}$ at week $12 \quad(\mathrm{p}=0.011)$. Sitagliptin, but not voglibose, increased serum Cre, uric acid and cys-C. Both agents lowered serum triglyceride levels, whereas voglibose, but not sitagliptin, significantly increased LDL-C. Voglibose significantly increased TNF- $\alpha$ levels, whereas sitagliptin, rather, tended to decrease TNF- $\alpha$ levels. Both agents significantly increased adiponectin levels. In stratified analyses on each concomitant therapy, there was no significant difference in glycemic parameters (see online supplementary figure S2). SU significantly increased neutrophils and decreased diastolic blood pressure compared to BG in the sitagliptin group (data not shown).

Factors predicting the effects of sitagliptin and voglibose are shown in table 3 . In the sitagliptin group, there was a significant correlation between $\triangle \mathrm{HbA} 1 \mathrm{c}$ and baseline levels of 1,5-AG ( $\mathrm{rs}=0.338, \mathrm{p}=0.000)$, HbA1c $(\mathrm{rs}=-0.589, \mathrm{p}=0.000)$ and adiponectin $(\mathrm{r}=0.223, \mathrm{p}=0.015$; table 3 ). There was no predicting factor in the voglibose group. In a multiple regression analysis, only baseline HbA1c was the independent factor of $\Delta \mathrm{HbA} 1 \mathrm{c}$ in the sitagiptin group $\left(\beta=-0525, p=0.000\right.$, adjusted $\left.R^{2}=0.268\right)$.

\section{Changes in fatty acid composition in serum lipids}

Sitagliptin, but not voglibose, significantly decreased serum levels of total polyunsaturated fatty acids, including linoleic acid and total $\omega 6$ fatty acids. Voglibose, but not sitagliptin, significantly decreased total saturated fatty acids (including palmitic acid and stearic acid), total monounsaturated fatty acids (including palmitoleic acid and oleic acid) and some polyunsaturated fatty acids (such as $\gamma$-linolenic acid, 5,8,11-eicosatrienoic acid, dihomo- $\gamma$-linolenic acid, docosatetraenoic acid and docosapentaenoic acid). Voglibose significantly decreased the activity of $\Delta-6$ desaturase and increased that of $\Delta-5$ desaturase (table 4). No correlation was observed between $\triangle \mathrm{HbA} 1 \mathrm{c}$ and eicosapentaenoic acid (EPA) levels at baseline in the sitagliptin group (table 3 ).

\section{Adverse events}

The incidence of AEs was significantly lower in the sitagliptin group. This difference was attributable to the decreased incidence of gastrointestinal AEs, such as heartburn, abdominal pain, constipation, loose stool, diarrhea, meteorism and flatulence. Most AEs were mild or moderate but one patient in the voglibose group discontinued the treatment due to diarrhea. The incidence of hypoglycemia was low and similar in both groups. All incidences of hypoglycemia in this study were mild or moderate in severity, but one patient in the sitagliptin group discontinued the treatment due to hypoglycemia. Four serious adverse events (SAEs)—inguinal hernia, heart failure, pancreatitis and urinary tract infectionoccurred in the voglibose group, but were considered not related to the study. Due to these SAEs, three patients discontinued the agents (see online supplementary table $\mathrm{S} 2$ ).

\section{DISCUSSION}

This study directly compared HbAlc and the pleiotropic effects of sitagliptin with voglibose added to concurrent 
Table 2 Changes in the characteristics of patients between baseline and 12 weeks

\begin{tabular}{|c|c|c|c|c|c|c|c|c|c|}
\hline \multirow[b]{2}{*}{ Parameter } & \multirow[b]{2}{*}{$\mathbf{n}$} & \multicolumn{2}{|l|}{ Sitagliptin } & \multirow[b]{2}{*}{ p Value* } & \multirow[b]{2}{*}{$\mathbf{n}$} & \multicolumn{2}{|l|}{ Voglibose } & \multirow[b]{2}{*}{ p Value* } & \multirow[b]{2}{*}{ p Valuet } \\
\hline & & Baseline & 12-week & & & Baseline & 12-week & & \\
\hline Body weight (kg) & 120 & $63.8 \pm 13.6$ & $63.7 \pm 13.3$ & 0.842 & 120 & $65.8 \pm 15.2$ & $65.3 \pm 15.1$ & 0.025 & 0.126 \\
\hline BMI & 118 & $24.9 \pm 4.5$ & $24.9 \pm 4.4$ & 0.777 & 119 & $25.1 \pm 4.5$ & $24.9 \pm 4.4$ & 0.024 & 0.086 \\
\hline Waist (cm) & 116 & $88.7 \pm 10.5$ & $88.2 \pm 10.0$ & 0.195 & 120 & $91.0 \pm 11.7$ & $90.0 \pm 11.1$ & 0.013 & 0.363 \\
\hline $\mathrm{SBP}(\mathrm{mm} \mathrm{Hg})$ & 120 & $130.0 \pm 16.8$ & $129.5 \pm 17.1$ & 0.998 & 121 & $131.6 \pm 18.5$ & $128.9 \pm 16.7$ & 0.067 & 0.265 \\
\hline $\mathrm{DBP}(\mathrm{mm} \mathrm{Hg})$ & 120 & $76.0 \pm 12.1$ & $75.4 \pm 12.1$ & 0.576 & 121 & $75.1 \pm 12.9$ & $74.4 \pm 12.5$ & 0.689 & 0.918 \\
\hline WBC $\left(/ \mathrm{mm}^{3}\right)$ & 120 & $5815 \pm 1362$ & $6057 \pm 1590$ & 0.050 & 119 & $5985 \pm 1762$ & $5940 \pm 1975$ & 0.315 & 0.037 \\
\hline Neutrophils $\left(/ \mathrm{mm}^{3}\right)$ & 108 & $3279 \pm 1015$ & $3570 \pm 1096$ & 0.008 & 107 & $3485 \pm 1313$ & $3431 \pm 1587$ & 0.193 & 0.007 \\
\hline Eosinophils $\left(/ \mathrm{mm}^{3}\right)$ & 105 & $156 \pm 120$ & $151 \pm 120$ & 0.000 & 105 & $163 \pm 108$ & $164 \pm 114$ & 0.821 & 0.074 \\
\hline Basophils $\left(/ \mathrm{mm}^{3}\right)$ & 105 & $30 \pm 23$ & $31 \pm 23$ & 0.359 & 105 & $32 \pm 21$ & $34 \pm 28$ & 0.864 & 0.247 \\
\hline Lymphocytes $\left(/ \mathrm{mm}^{3}\right)$ & 105 & $1951 \pm 607$ & $1866 \pm 586$ & 0.007 & 105 & $2041 \pm 723$ & $2023 \pm 766$ & 0.772 & 0.023 \\
\hline Monocytes $\left(/ \mathrm{mm}^{3}\right)$ & 105 & $323 \pm 113$ & $345 \pm 122$ & 0.004 & 105 & $339 \pm 139$ & $340 \pm 150$ & 0.270 & 0.009 \\
\hline $\operatorname{PLT}\left(10^{4} / \mathrm{mm}^{3}\right)$ & 120 & $21.0 \pm 5.5$ & $20.8 \pm 5.6$ & 0.281 & 119 & $21.8 \pm 6.0$ & $21.3 \pm 5.8$ & 0.084 & 0.574 \\
\hline $\operatorname{RBC}\left(10^{3} / \mathrm{mm}^{3}\right)$ & 120 & $458.4 \pm 43.7$ & $459.2 \pm 45.4$ & 0.723 & 119 & $454.1 \pm 52.1$ & $457.2 \pm 50.3$ & 0.124 & 0.612 \\
\hline $\mathrm{Hb}(\mathrm{g} / \mathrm{mL})$ & 120 & $13.9 \pm 1.6$ & $14.0 \pm 1.8$ & 0.943 & 119 & $13.9 \pm 1.6$ & $14.0 \pm 1.5$ & 0.548 & 0.882 \\
\hline $\mathrm{Ht}(\%)$ & 120 & $41.6 \pm 4.1$ & $41.7 \pm 4.4$ & 0.565 & 119 & $41.3 \pm 4.2$ & $41.8 \pm 4.0$ & 0.030 & 0.399 \\
\hline AST (IU/L) & 120 & $26 \pm 13$ & $26 \pm 13$ & 0.554 & 120 & $26 \pm 16$ & $25 \pm 11$ & 0.961 & 0.776 \\
\hline ALT (IU/L) & 120 & $32 \pm 25$ & $30 \pm 21$ & 0.459 & 120 & $30 \pm 26$ & $30 \pm 20$ & 0.505 & 0.309 \\
\hline ALP (IU/L) & 120 & $236 \pm 71$ & $226 \pm 76$ & 0.000 & 118 & $237 \pm 91$ & $236 \pm 101$ & 0.168 & 0.074 \\
\hline $\mathrm{BAP}(\mu \mathrm{g} / \mathrm{L})$ & 116 & $12.6 \pm 5.6$ & $12.3 \pm 5.6$ & 0.140 & 116 & $12.7 \pm 5.5$ & $12.5 \pm 4.9$ & 0.832 & 0.186 \\
\hline$\gamma$-GTP (IU/L) & 120 & $44 \pm 50$ & $49.2 \pm 87.6$ & 0.836 & 119 & $49 \pm 57$ & $47 \pm 51$ & 0.011 & 0.051 \\
\hline CK (IU/L) & 117 & $105.5 \pm 71.6$ & $105.2 \pm 68.0$ & 0.920 & 116 & $109.2 \pm 59.5$ & $107.4 \pm 54.5$ & 0.552 & 0.720 \\
\hline BUN (mg/dL) & 120 & $14.9 \pm 4.1$ & $15.0 \pm 4.6$ & 0.838 & 120 & $15.3 \pm 4.9$ & $14.5 \pm 4.9$ & 0.041 & 0.166 \\
\hline $\mathrm{Cr}(\mathrm{mg} / \mathrm{dL})$ & 120 & $0.71 \pm 0.19$ & $0.74 \pm 0.19$ & 0.000 & 120 & $0.74 \pm 0.27$ & $0.76 \pm 0.27$ & 0.129 & 0.199 \\
\hline $\mathrm{UA}(\mathrm{mg} / \mathrm{dL})$ & 119 & $5.08 \pm 1.14$ & $5.30 \pm 1.24$ & 0.001 & 120 & $5.13 \pm 1.40$ & $5.28 \pm 1.40$ & 0.073 & 0.328 \\
\hline Cystatin C (mg/L) & 114 & $0.82 \pm 0.18$ & $0.85 \pm 0.19$ & 0.001 & 112 & $0.86 \pm 0.23$ & $0.86 \pm 0.23$ & 0.177 & 0.087 \\
\hline eGFRcreat $\left(\mathrm{mL} / \mathrm{min} / 1.73 \mathrm{~m}^{2}\right)$ & 120 & $85.0 \pm 28.4$ & $80.6 \pm 26.5$ & 0.000 & 120 & $80.4 \pm 24.1$ & $78.3 \pm 23.4$ & 0.069 & 0.203 \\
\hline eGFRcys (mL/min/1.73 $\left.\mathrm{m}^{2}\right)$ & 114 & $91.1 \pm 23.2$ & $91.1 \pm 29.3$ & 0.969 & 112 & $87.9 \pm 25.0$ & $88.5 \pm 22.9$ & 0.626 & 0.132 \\
\hline eGFRaverage $\left(\mathrm{mL} / \mathrm{min} / 1.73 \mathrm{~m}^{2}\right)$ & 114 & $88.0 \pm 23.3$ & $85.6 \pm 24.6$ & 0.006 & 111 & $83.7 \pm 22.2$ & $83.4 \pm 20.8$ & 0.687 & 0.053 \\
\hline $\mathrm{TC}(\mathrm{mg} / \mathrm{dL})$ & 120 & $185.1 \pm 33.4$ & $184.9 \pm 39.0$ & 0.910 & 118 & $191.6 \pm 32.4$ & $193.6 \pm 40.8$ & 0.066 & 0.272 \\
\hline HDL-C (mg /dL) & 118 & $52.7 \pm 15.4$ & $52.3 \pm 14.8$ & 0.873 & 118 & $54.9 \pm 18.0$ & $54.8 \pm 18.3$ & 0.739 & 0.712 \\
\hline Triglyceride (mg/dL) & 120 & $136.0 \pm 83.1$ & $129.8 \pm 85.5$ & 0.098 & 120 & $144.2 \pm 103.2$ & $129.3 \pm 79.0$ & 0.015 & 0.450 \\
\hline LDL-C (mg/dL) & 118 & $104.9 \pm 29.6$ & $106.5 \pm 34.1$ & 0.499 & 117 & $107.5 \pm 26.5$ & $112.7 \pm 36.5$ & 0.001 & 0.026 \\
\hline sdLDL (mg/dL) & 118 & $36.8 \pm 15.4$ & $34.9 \pm 15.1$ & 0.134 & 120 & $38.0 \pm 16.6$ & $38.3 \pm 17.6$ & 0.831 & 0.220 \\
\hline IRI (IU/L) & 116 & $8.46 \pm 8.20$ & $8.69 \pm 9.37$ & 0.342 & 118 & $14.1 \pm 65.1$ & $14.2 \pm 69.5$ & 0.028 & 0.039 \\
\hline $\mathrm{CPR}(\mathrm{ng} / \mathrm{mL})$ & 118 & $2.10 \pm 0.88$ & $2.04 \pm 0.84$ & 0.421 & 120 & $2.08 \pm 1.03$ & $2.05 \pm 1.13$ & 0.634 & 0.715 \\
\hline HMW adiponectin ( $\mu \mathrm{g} / \mathrm{dL})$ & 118 & $3.17 \pm 2.30$ & $3.50 \pm 2.57$ & 0.000 & 120 & $3.53 \pm 3.65$ & $3.74 \pm 3.53$ & 0.000 & 0.161 \\
\hline Hypersensitive TNF- $\alpha$ (pg/mL) & 118 & $3.11 \pm 12.47$ & $2.23 \pm 5.21$ & 0.079 & 120 & $1.42 \pm 1.87$ & $1.55 \pm 1.83$ & 0.000 & 0.538 \\
\hline Leptin (ng/mL) & 118 & $8.26 \pm 6.90$ & $8.27 \pm 7.17$ & 0.561 & 120 & $9.02 \pm 9.28$ & $8.21 \pm 6.59$ & 0.694 & 0.540 \\
\hline HOMA-IR & 115 & $3.30 \pm 3.44$ & $2.98 \pm 3.02$ & 0.056 & 117 & $5.21 \pm 23.02$ & $5.52 \pm 29.02$ & 0.003 & 0.443 \\
\hline HOMA- $\beta$ & 115 & $36.0 \pm 32.8$ & $47.2 \pm 57.6$ & 0.000 & 117 & $63.7 \pm 299.6$ & $59.5 \pm 237.4$ & 0.408 & 0.002 \\
\hline SUIT index & 117 & $39.5 \pm 30.4$ & $45.9 \pm 28.3$ & 0.000 & 118 & $38.0 \pm 22.1$ & $40.9 \pm 23.8$ & 0.004 & 0.047 \\
\hline
\end{tabular}




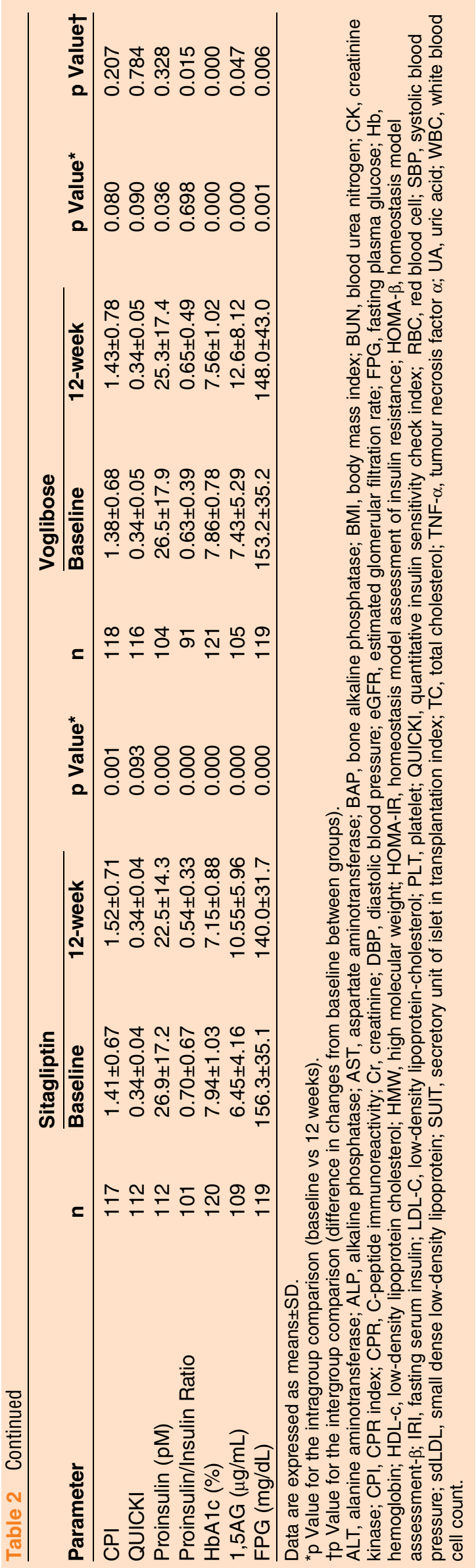

treatment in Japanese patients with type 2 diabetes who could not achieve adequate glycemic control through diet therapy or a single OHA. The novelty of the present study is as follows: First, dynamic randomization is methodologically novel. It is useful to adjust for demographic differences between each group. In this open-label, randomized, parallel-group study with dynamic allocation, we compared sitagliptin with voglibose, not only as a monotherapy, but also as an add-on therapy to SU, BG or TZD. Second, pleiotropic effects of sitagliptin and voglibose include previously yet-recognized findings.

Regarding the primary endpoint, sitagliptin was superior to voglibose in lowering HbAlc levels in monotherapy and in combination with each concurrent agent. A similar reduction in $\mathrm{HbAlc}$ was also observed in previous 12-week studies. ${ }^{18-20}$

Regarding the secondary end points, sitagliptin and voglibose exerted unique pleiotropic effects in the present study. Sitagliptin, but not voglibose, significantly increased the markers of $\beta$-cell function (HOMA- $\beta$ and proinsulin/insulin ratio). Preclinical studies have shown that GLP-1 stimulates $\beta$-cell differentiation and proliferation, inhibits apoptosis of $\beta$-cells, ${ }^{21}{ }^{22}$ and stimulates $\beta$-cell neogenesis and survival in streptozotocin-treated rats. ${ }^{23}$ In fact, several reviews have indicated that DPP-4 inhibitors consistently improve markers of $\beta$-cell function in type 2 diabetes patients. ${ }^{20} 24{ }^{25} \mathrm{~A}$ decrease in the fasting proinsulin-to-insulin ratio, consistent with improved $\beta$-cell function, was observed in association with sitagliptin treatment in a previous study. ${ }^{26}$

Sitagliptin compared with voglibose significantly reduced the counts of lymphocytes and increased those of neutrophils in the present study, as observed in the previous study. ${ }^{27}$ DPP-4 is highly expressed by T-cells, especially CD4+ T-cells. Sitagliptin decreases CD4+ T-cells in a glucose-independent manner. ${ }^{27}$ Whether DPP-4 inhibitors suppress immunity by reducing the number of circulating CD4+ T-cells should be examined in future. Sitagliptin significantly increased serum levels of Cre, cys-C and uric acid, and decreased eGFRcreat, whereas voglibose had no effect on these parameters in the present study. These results might relate to the Na-diuretic action of GLP- $1,{ }^{28}$ although we observed no reduction in blood pressure in the present study. Therefore, it is possible that sitagliptin impairs renal function. In fact, during a much longer, 54-week study, it was found that $18.8 \%$ of patients in the sitagliptin group with moderate renal insufficiency at baseline transitioned to severe renal insufficiency status over the course of the study. ${ }^{29}$ On the other hand, in our study, deterioration of eGFRcys was not observed. After 12 weeks, sitagliptin, but not voglibose, decreased ALP levels relative to baseline without affecting BAP levels. Although it is not certain whether this sitagliptinmediated decrease in ALP is related to bone metabolism, the decrease in ALP from baseline significantly correlated with a decrease in HbAlc levels, as observed in previous studies. ${ }^{30} 31$ 
Table 3 Factors associated with a change in $\mathrm{HbA} 1 \mathrm{c}$

\begin{tabular}{|c|c|c|c|c|}
\hline & \multicolumn{2}{|c|}{ Sitagliptin } & \multicolumn{2}{|c|}{ Voglibose } \\
\hline & rs & p Value & rs & p Value \\
\hline \multicolumn{5}{|l|}{ Baseline } \\
\hline Body weight (kg) & -0.051 & 0.577 & -0.082 & 0.374 \\
\hline Body mass index & -0.142 & 0.126 & -0.08 & 0.390 \\
\hline Fasting plasma glucose (mg/dL) & -0.113 & 0.222 & 0.107 & 0.246 \\
\hline 1,5 AG $(\%)$ & 0.338 & 0.000 & -0.034 & 0.714 \\
\hline $\mathrm{HbA1c}(\%)$ & -0.589 & 0.000 & -0.121 & 0.185 \\
\hline Total cholesterol (mg/dL) & 0.050 & 0.588 & 0.009 & 0.948 \\
\hline Fasting serum insulin (IU/L) & -0.092 & 0.328 & -0.079 & 0.392 \\
\hline CPR (ng/mL) & -0.101 & 0.275 & -0.004 & 0.965 \\
\hline HMW adiponectin $(\mu \mathrm{g} / \mathrm{mL})$ & 0.223 & 0.015 & 0.137 & 0.137 \\
\hline $\mathrm{CPI}$ & -0.048 & 0.609 & -0.038 & 0.684 \\
\hline HOMAIR & -0.128 & 0.171 & 0.114 & 0.222 \\
\hline HOMA- $\beta$ & -0.016 & 0.861 & 0.033 & 0.722 \\
\hline EPA (ng/mL) & -0.064 & 0.490 & 0.062 & 0.502 \\
\hline $\mathrm{DHA}(\mathrm{ng} / \mathrm{mL})$ & -0.077 & 0.118 & -0.078 & 0.396 \\
\hline \multicolumn{5}{|l|}{ Change from baseline } \\
\hline$\Delta \mathrm{FPG}$ & 0.386 & 0.000 & 0.421 & 0.000 \\
\hline$\Delta \mathrm{BW}$ & 0.212 & 0.020 & 0.047 & 0.609 \\
\hline$\Delta \mathrm{BMI}$ & 0.206 & 0.025 & 0.058 & 0.533 \\
\hline$\triangle \mathrm{ALP}$ & 0.269 & 0.003 & 0.187 & 0.042 \\
\hline$\Delta \mathrm{TC}$ & 0.231 & 0.011 & -0.062 & 0.502 \\
\hline$\Delta$ LDLC & 0.266 & 0.004 & 0.151 & 0.103 \\
\hline$\Delta \mathrm{TG}$ & 0.084 & 0.362 & -0.152 & 0.098 \\
\hline$\Delta \mathrm{HMW}$ adiponectin & -0.310 & 0.001 & -0.346 & 0.000 \\
\hline$\Delta \mathrm{HOMA}-\mathrm{IR}$ & 0.233 & 0.012 & 0.105 & 0.262 \\
\hline$\Delta \mathrm{HOMA}-\beta$ & -0.304 & 0.001 & -0.222 & 0.016 \\
\hline$\Delta$ SUIT index & -0.377 & 0.000 & -0.261 & 0.004 \\
\hline$\triangle \mathrm{QUICKI}$ & -0.185 & 0.047 & -0.175 & 0.060 \\
\hline$\Delta \mathrm{CPI}$ & -0.235 & 0.011 & -0.156 & 0.091 \\
\hline$\Delta$ Proinsulin insulin ratio & 0.199 & 0.046 & 0.177 & 0.094 \\
\hline$\triangle \mathrm{EPA}$ & -0.010 & 0.914 & -0.062 & 0.502 \\
\hline$\triangle \mathrm{DHA}$ & 0.073 & 0.430 & -0.065 & 0.482 \\
\hline
\end{tabular}

AG, anhydroglucitol; ALP, alkaline phosphatase; BMI, body mass index; BW, body weight; CPR, C-peptide immunoreactivity; DHA, docosahexaenoic acid; EPA, eicosapentaenoic acid; FPG, fasting plasma glucose; HbA1c, hemoglobin A1c; HOMA-IR, homeostasis model assessment of insulin resistance; HOMA- $\beta$, homeostasis model assessment- $\beta$; HMW, high molecular weight; LDLC, low-density lipoprotein cholesterol; TC, total cholesterol; TG, triglyceride.

Both sitagliptin and voglibose significantly increased plasma adiponectin levels, as stated in previous reports. $^{32} 33$ There was a negative correlation between $\Delta$ HbAlc and $\Delta$ adiponectin (table 3 ), suggesting that glycemic control at least partly contributes to the increase in adiponectin levels. The increased adiponectin levels might improve endothelial function and likely yield antiatherosclerotic effects. ${ }^{34}$ In addition, baseline levels of adiponectin were negatively correlated with $\triangle \mathrm{HbAlc}$ only in the sitagliptin group, suggesting that adiponectin level might be a predictive maker for the effect of sitagliptin in glycemic control. Serum EPA concentrations are reported to be associated with the glucose-lowering effect of DPP-IV inhibitors in Japanese patients with type 2 diabetes. ${ }^{35}$ However, in our study, baseline EPA levels were not correlated with the change in HbAlc in the sitagliptin group (table 3). On the other hand, sitagliptin significantly decreased polyunsaturated fatty acids, especially $\omega 6$ fatty acids, whereas voglibose altered serum levels of many kinds of fatty acids, unlike in a previous study with acarbose. ${ }^{36}$ Notably, voglibose, but not sitagliptin, increased $\Delta-5$ desaturase activity. Several crosssectional studies showed that the $\Delta-5$ desaturase activity index, which refers to the ratio of arachidonic acids to dihomo- $\gamma$-linolenic acids, is positively associated with insulin sensitivity ${ }^{37} 38$ and the onset of newly diagnosed type 2 diabetes, ${ }^{39}$ and is negatively associated with several metabolic risk factors in patients with metabolic syndrome. ${ }^{40}$ High $\Delta-5$ desaturase activity was associated with reduced coronary heart disease risk. ${ }^{41}$ Conversely, voglibose decreased $\Delta-6$ desaturase activity. $\Delta-6$ desaturase activity was associated with an increased probability of metabolic syndrome. ${ }^{40}$ These findings suggest the possibility that voglibose, rather than sitagliptin, might reduce coronary heart disease risk by altering fatty acids profiling. However, as a limitation, because the present 3-month, open-label study was designed to compare the antihyperglycemic effects of sitagliptin and voglibose, 
Table 4 Changes in plasma fatty acid composition between baseline and 12 weeks

\begin{tabular}{|c|c|c|c|c|c|c|c|c|c|c|}
\hline \multirow{2}{*}{ Parameter } & & \multirow[b]{2}{*}{$\mathbf{n}$} & \multicolumn{2}{|l|}{ Sitagliptin } & \multirow[b]{2}{*}{ p Value* } & \multirow[b]{2}{*}{$\mathbf{n}$} & \multicolumn{2}{|l|}{ Voglibose } & \multirow[b]{2}{*}{ p Value* } & \multirow[b]{2}{*}{ p Value } \\
\hline & & & Baseline & 12-week & & & Baseline & 12-week & & \\
\hline Lauric acid & $\mathrm{C} 12: 0(\mathrm{ng} / \mathrm{mL})$ & 118 & $2.3 \pm 2.2$ & $2.3 \pm 2.3$ & 0.555 & 120 & $2.5 \pm 2.1$ & $2.2 \pm 2.3$ & 0.139 & 0.592 \\
\hline Myristic acid & $\mathrm{C} 14: 0(\mathrm{ng} / \mathrm{mL})$ & 118 & $29.9 \pm 18.9$ & $28.5 \pm 19.3$ & 0.147 & 120 & $33.1 \pm 23.0$ & $30.0 \pm 22.8$ & 0.012 & 0.356 \\
\hline Palmitic acid & C16:0 (ng/mL) & 118 & $746.7 \pm 259.6$ & $709.8 \pm 254.1$ & 0.019 & 120 & $796.9 \pm 268.7$ & $747.9 \pm 265.4$ & 0.001 & 0.494 \\
\hline Palmitoleic acid & $\mathrm{C} 16: 1 \omega 7(\mathrm{ng} / \mathrm{mL})$ & 118 & $80.3 \pm 46.2$ & $77.0 \pm 51.6$ & 0.130 & 120 & $89.7 \pm 51.6$ & $82.0 \pm 53.7$ & 0.000 & 0.049 \\
\hline Stearic acid & C18:0 (ng/mL) & 118 & $214.7 \pm 53.6$ & $212.0 \pm 28.7$ & 0.532 & 120 & $224.2 \pm 57.7$ & $218.2 \pm 61.8$ & 0.033 & 0.291 \\
\hline Oleic acid & $\mathrm{C} 18: 1 \omega 9(\mathrm{ng} / \mathrm{mL})$ & 118 & $656.2 \pm 236.6$ & $653.2 \pm 260.1$ & 0.799 & 120 & $714.9 \pm 295.4$ & $671.7 \pm 268.3$ & 0.049 & 0.194 \\
\hline Linoleic acid & 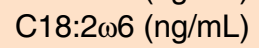 & 118 & $774.4 \pm 182.1$ & $736.3 \pm 188.6$ & 0.021 & 120 & $798.6 \pm 208.2$ & $807.2 \pm 244.4$ & 0.902 & 0.143 \\
\hline$\gamma$-linolenic acid & $\mathrm{C} 18: 3 \omega 6(\mathrm{ng} / \mathrm{mL})$ & 118 & $11.4 \pm 6.5$ & $10.8 \pm 6.0$ & 0.941 & 120 & $11.9 \pm 6.9$ & $10.2 \pm 5.5$ & 0.000 & 0.023 \\
\hline$\alpha$-Linolenic acid & $\mathrm{C} 18: 3 \omega 3(\mathrm{ng} / \mathrm{mL})$ & 118 & $27.6 \pm 12.5$ & $25.9 \pm 11.1$ & 0.010 & 120 & $27.3 \pm 15.0$ & $27.2 \pm 16.3$ & 0.331 & 0.164 \\
\hline Arachidic acid & $\mathrm{C} 20: 0(\mathrm{ng} / \mathrm{mL})$ & 118 & $7.2 \pm 1.3$ & $7.3 \pm 1.6$ & 0.876 & 120 & $7.6 \pm 1.6$ & $7.7 \pm 1.7$ & 0.935 & 0.935 \\
\hline Eicosenoic acid & $\mathrm{C} 20: 1 \omega 9(\mathrm{ng} / \mathrm{mL})$ & 118 & $5.5 \pm 2.0$ & $5.3 \pm 2.2$ & 0.562 & 120 & $6.1 \pm 6.8$ & $6.3 \pm 6.9$ & 0.306 & 0.274 \\
\hline Eicosadienoic acid & $\mathrm{C} 20: 2 \omega 6(\mathrm{ng} / \mathrm{mL})$ & 118 & $5.9 \pm 1.8$ & $5.9 \pm 2.0$ & 0.599 & 120 & $6.3 \pm 2.0$ & $6.3 \pm 21$ & 0.764 & 0.929 \\
\hline 5-8-11Eicosatrienoic acid & $\mathrm{C} 20: 3 \omega 9(\mathrm{ng} / \mathrm{mL})$ & 118 & $2.2 \pm 1.4$ & $2.2 \pm 1.6$ & 0.549 & 120 & $2.8 \pm 2.6$ & $2.5 \pm 2.4$ & 0.008 & 0.116 \\
\hline Dihomo- $\gamma$-linolenic acid & $\mathrm{C} 20: 3 \omega 6(\mathrm{ng} / \mathrm{mL})$ & 118 & $38.8 \pm 13.2$ & $39.7 \pm 16.4$ & 0.260 & 120 & $42.4 \pm 15.5$ & $39.9 \pm 12.7$ & 0.005 & 0.010 \\
\hline Arachidonic acid & $\mathrm{C} 20: 4 \omega 6(\mathrm{ng} / \mathrm{mL})$ & 118 & $173.2 \pm 48.7$ & $172.0 \pm 51.3$ & 0.706 & 120 & $184.5 \pm 46.5$ & $183.5 \pm 44.6$ & 0.691 & 0.898 \\
\hline Eicosapentaenoic acid & $\mathrm{C} 20: 5 \omega 3(\mathrm{ng} / \mathrm{mL})$ & 118 & $80.6 \pm 48.3$ & $79.7 \pm 43.5$ & 0.884 & 120 & $81.2 \pm 70.0$ & $85.5 \pm 78.4$ & 0.659 & 0.955 \\
\hline Behenic acid & C22:0 (ng/mL) & 118 & $17.9 \pm 3.3$ & $17.9 \pm 3.6$ & 0.838 & 120 & $32.1 \pm 3.7$ & $19.1 \pm 4.3$ & 0.465 & 0.651 \\
\hline Erucic acid & $\mathrm{C} 22: 1 \omega 9(\mathrm{ng} / \mathrm{mL})$ & 118 & $1.6 \pm 0.8$ & $1.6 \pm 0.7$ & 0.613 & 120 & $1.8 \pm 0.9$ & $1.7 \pm 0.9$ & 0.768 & 0.291 \\
\hline Docosatetraenoic acid & $\mathrm{C} 22: 4 \omega 6(\mathrm{ng} / \mathrm{mL})$ & 118 & $5.2 \pm 2.2$ & $5.1 \pm 2.6$ & 0.248 & 120 & $5.5 \pm 2.3$ & $5.1 \pm 1.9$ & 0.011 & 0.306 \\
\hline Docosapentaenoic acid & $\mathrm{C} 22: 5 \omega 3(\mathrm{ng} / \mathrm{mL})$ & 118 & $25.2 \pm 10.0$ & $24.3 \pm 9.4$ & 0.399 & 120 & $25.8 \pm 13.1$ & $24.0 \pm 13.5$ & 0.004 & 0.955 \\
\hline Lignoceric acid & $\mathrm{C} 24: 0(\mathrm{ng} / \mathrm{mL})$ & 118 & $16.3 \pm 2.8$ & $16.3 \pm 3.3$ & 0.775 & 120 & $17.5 \pm 3.4$ & $17.8 \pm 3.9$ & 0.423 & 0.598 \\
\hline Docosahexaenoic acid & $\mathrm{C} 22: 6 \omega 3(\mathrm{ng} / \mathrm{mL})$ & 118 & $175.2 \pm 65.3$ & $169.5 \pm 58.7$ & 0.305 & 120 & $175.2 \pm 94.5$ & $167.7 \pm 96.1$ & 0.095 & 0.531 \\
\hline Nervonic acid & $\mathrm{C} 24: 1 \omega 9(\mathrm{ng} / \mathrm{mL})$ & 118 & $34.8 \pm 7.5$ & $34.5 \pm 7.5$ & 0.357 & 120 & $37.0 \pm 8.2$ & $37.7 \pm 8.0$ & 0.028 & 0.028 \\
\hline $\mathrm{EPA}+\mathrm{DHA}$ & $(\mathrm{ng} / \mathrm{mL})$ & 118 & $255.9 \pm 107.5$ & $249.2 \pm 92.6$ & 0.536 & 120 & $256.3 \pm 160.3$ & $253.1 \pm 169.4$ & 0.436 & 0.782 \\
\hline EPA/AA ratio & & 118 & $0.49 \pm 0.31$ & $0.49 \pm 0.30$ & 0.705 & 120 & $0.44 \pm 0.32$ & $0.044 \pm 0.32$ & 0.435 & 0.895 \\
\hline Total $\omega 3$ fatty acids & (ng/mL) & 118 & $308.7 \pm 121.9$ & $299.0 \pm 105.3$ & 0.370 & 120 & $309.4 \pm 181.0$ & $304.3 \pm 191.6$ & 0.308 & 0.735 \\
\hline Total $\omega 6$ fatty acids & (ng/mL) & 118 & $1008.7 \pm 224.8$ & $969.8 \pm 237.7$ & 0.024 & 120 & $1049.2 \pm 238.2$ & $1052.3 \pm 273.9$ & 0.684 & 0.239 \\
\hline Total $\omega 9$ fatty acids & (ng/mL) & 118 & $700.2 \pm 239.2$ & $696.8 \pm 263.6$ & 0.794 & 120 & $762.6 \pm 300.8$ & $720.0 \pm 272.5$ & 0.053 & 0.210 \\
\hline$\omega 3 / \omega 6$ ratio & & 118 & $0.32 \pm 0.13$ & $0.32 \pm 0.11$ & 0.236 & 120 & $0.30 \pm 0.14$ & $0.30 \pm 0.14$ & 0.409 & 0.151 \\
\hline Total saturated fatty acids & (ng/mL) & 118 & $1034.9 \pm 330.7$ & $994.1 \pm 330.3$ & 0.050 & 120 & $1101.1 \pm 346.5$ & $1043.0 \pm 348.1$ & 0.002 & 0.515 \\
\hline Monounsaturated fatty acids & (ng/mL) & 118 & $778.3 \pm 276.8$ & $771.7 \pm 305.2$ & 0.762 & 120 & $854.3 \pm 346.8$ & $799.5 \pm 306.6$ & 0.020 & 0.132 \\
\hline Polyunsaturated fatty acids & (ng/mL) & 118 & $1319.5 \pm 277.3$ & $1270.9 \pm 289.2$ & 0.014 & 120 & $1361.4 \pm 336.2$ & $1359.0 \pm 384.4$ & 0.562 & 0.233 \\
\hline \multicolumn{2}{|c|}{$\delta$-5desaturase $(20: 4 \omega 6 / 20: 3 \omega 6)$} & 118 & $4.73 \pm 1.42$ & $4.72 \pm 1.62$ & 0.595 & 120 & $4.78 \pm 1.77$ & $4.97 \pm 1.64$ & 0.014 & 0.031 \\
\hline \multicolumn{2}{|c|}{$\delta$-6desaturase (18:3 $\omega 6 / 18: 2 \omega 6)$} & 118 & $0.015 \pm 0.008$ & $0.015 \pm 0.007$ & 0.321 & 120 & $0.016 \pm 0.01$ & $0.014 \pm 0.009$ & 0.009 & 0.007 \\
\hline
\end{tabular}

Data are expressed as means \pm SD.

${ }^{*} \mathrm{p}$ Value for the intragroup comparison (baseline vs 12 weeks)

tp Value for the intergroup comparison (difference in changes from baseline between groups)

AA, arachidonic acid; DHA, docosahexaenoic acid; EPA, eicosapentaenoic acid. 
the study duration may be insufficient to evaluate some of the pleiotropic effects. In the subgroup analysis, concomitant antidiabetic agents did not affect the results in glycemic parameters.

In summary, we showed that sitagliptin is superior to voglibose in terms of improving glycemic control as a first/second-line therapy in Japanese people with type 2 diabetes. However, both agents exert unique pleiotropic effects on surrogate cardiovascular risks, which suggests a theoretical basis for potential benefits through combined therapy. A large-scale clinical trial on cardiovascular events is required to test this hypothesis.

\section{Author affiliations}

${ }^{1}$ Department of Endocrinology and Metabolism, Kanazawa University Graduate School of Medical Sciences, Kanazawa, Ishikawa, Japan

${ }^{2}$ Department of Disease Control and Homeostasis, Kanazawa University Graduate School of Medical Sciences, Kanazawa, Ishikawa, Japan ${ }^{3}$ ERA-DM Chapter 1 Study Group, Kanazawa, Ishikawa, Japan

Collaborators Clinical Centres for the ERA-DM study Chapter 1 group: Department of Disease Control and Homeostasis, Kanazawa University Graduate School of Medical Science (Kanazawa, Ishikawa), Municipal Tsuruga Hospital (Tsuruga, Fukui), Koshino Hospital (Kanazawa, Ishikawa), Ishida Hospital (Kanazawa, Ishikawa), Handa Medical Clinic (Kanazawa, Ishikawa), Yumie Takeshita, MD PhD, Toshinari Takamura, MD PhD, Toshiki Otoda, MD $\mathrm{PhD}$; Ken-ichiro Kato MD, Hitomi Wakakuri, MD, Masayuki Yamada, MD, Hirofumi Misu, MD PhD, Shuichi Kaneko, MD PhD, Tsuguhito Ota, MD PhD, Takehiro Kanamori, MD, Yukiko Matsushima (coordinator), Shima Kitakata (coordinator); Public Hakui Hospital (Hakui, Ishikawa), Toshiki Otoda, MD PhD; Japanese Red Cross Kanazawa Hospital (Kanazawa, Ishikawa), Erika Hamaguchi, MD PhD, Yasuyuki Nishimura, MD PhD; Toyama City Hospital (Toyama, Toyama), Akiko Shimizu, MD PhD; Public Central Hospital of Matto Ishikawa (Matto, Ishikawa), Yuki Kita, MD PhD, Kozo Kawai, MD PhD; Kahoku Central Hospital (Kahoku, Ishikawa), Kensuke Mouri, MD; Fukui Saiseikai Hospital (Fukui, Fukui), Kosuke R Shima, MD, Yukihiro Bando, MD PhD; Kanazawa Municipal Hospital (Kanazawa, Ishikawa), Nobuhiko Koike, MD PhD.

Contributors TT is the guarantor of this study and, as such, had full access to all of the data, and takes responsibility for the integrity and accuracy of the data and the analysis. YM designed the study, analysed and interpreted the data, and wrote the manuscript. YT designed the study, recruited the patients, collected clinical information, analysed and interpreted the data, and wrote the manuscript. YK, TO, KK, HT-W, HA, AS, EH, YN and TK collected clinical information. SK initiated and organized the study. All the authors have read and approved the final manuscript.

Funding This work was supported by Grants-in-Aid from the Ministry of Education, Culture, Sports, Science, and Technology of Japan, and Research grants from ONO Pharmaceutical Co, Ltd (to TT and SK).

\section{Competing interests None declared.}

Patient consent Obtained.

Ethics approval Kanazawa University Hospital Institutional Review Board.

Provenance and peer review Not commissioned; externally peer reviewed.

Open Access This is an Open Access article distributed in accordance with the Creative Commons Attribution Non Commercial (CC BY-NC 4.0) license, which permits others to distribute, remix, adapt, build upon this work noncommercially, and license their derivative works on different terms, provided the original work is properly cited and the use is non-commercial. See: http:// creativecommons.org/licenses/by-nc/4.0/

\section{REFERENCES}

1. Ray KK, Seshasai SRK, Wijesuriya S, et al. Effect of intensive control of glucose on cardiovascular outcomes and death in patients with diabetes mellitus: a meta-analysis of randomised controlled trials. Lancet 2009;373:1765-72.

2. Inzucchi SE, Bergenstal RM, Buse JB, et al. Management of hyperglycemia in type 2 diabetes: a patient-centered approach: position statement of the American Diabetes Association (ADA) and the European Association for the Study of Diabetes (EASD). Diabetes Care 2012;35:1364-79.

3. Kirby M, Yu DMT, O'Connor S, et al. Inhibitor selectivity in the clinical application of dipeptidyl peptidase-4 inhibition. Clin Sci (Lond) 2010;118:31-41.

4. Karasik A, Aschner P, Katzeff $H$, et al. Sitagliptin, a DPP-4 inhibitor for the treatment of patients with type 2 diabetes: a review of recent clinical trials. Curr Med Res Opin 2008;24:489-96.

5. Raz I, Hanefeld M, Xu L, et al. Efficacy and safety of the dipeptidyl peptidase-4 inhibitor sitagliptin as monotherapy in patients with type 2 diabetes mellitus. Diabetologia 2006;49:2564-71.

6. Iwamoto $\mathrm{Y}$, Taniguchi T, Nonaka $\mathrm{K}$, et al. Dose-ranging efficacy of sitagliptin, a dipeptidyl peptidase-4 inhibitor, in Japanese patients with type 2 diabetes mellitus. Endocr J 2010;57:383-94.

7. Moritoh Y, Takeuchi K, Hazama M. Chronic Administration of Voglibose, an $\alpha$-Glucosidase Inhibitor, Increases Active Glucagon-Like Peptide-1 Levels by Increasing Its Secretion and Decreasing Dipeptidyl Peptidase-4 Activity in ob/ob Mice. J Pharmacol Exp Ther 2009;329:669-76.

8. Ranganath LMV. Delayed gastric emptying occurs following acarbose administration and is a further mechanism for its anti-hyperglycaemic effect. Diabet Med 1998;15:120-4.

9. [No authors listed]. Report of the expert committee on the diagnosis and classification of diabetes mellitus. Diabetes Care 1997;20:1183-97.

10. Japanese Society of Nephrology, ed. Clinical practice guidebook for diagnosis and treatment of chronic kidney disease 2012. Tokyo: Tokyo-igakusha, 2012.

11. Horio M. [Development of evaluation of kidney function and classification of chronic kidney disease (CKD) -including CKD clinical practice guide 2012]. Rinsho Byori 2013;61:616-21.

12. Wallace TM, Levy JC, Matthews DR. Use and abuse of HOMA modeling. Diabetes Care 2004;27:1487-95.

13. Iwata M, Maeda S, Kamura Y, et al. Genetic risk score constructed using 14 susceptibility alleles for type 2 diabetes is associated with the early onset of diabetes and may predict the future requirement of insulin injections among Japanese individuals. Diabetes Care 2012;35:1763-70.

14. Matthews DR, Hosker JP, Rudenski AS, et al. Homeostasis model assessment: insulin resistance and beta-cell function from fasting plasma glucose and insulin concentrations in man. Diabetologia 1985;28:412-19.

15. Yamada Y, Fukuda K, Fujimoto S, et al. SUIT, secretory units of islets in transplantation: an index for therapeutic management of islet transplanted patients and its application to type 2 diabetes. Diabetes Res Clin Pract 2006;74:222-6.

16. Katz A. Quantitative insulin sensitivity check index: a simple, accurate method for assessing insulin sensitivity in humans. J Clin Endocrinol Metab 2000;85:2402-10.

17. Corpeleijn E, Feskens EJM, Jansen EHJM, et al. Improvements in glucose tolerance and insulin sensitivity after lifestyle intervention are related to changes in serum fatty acid profile and desaturase activities: the SLIM study. Diabetologia 2006;49:2392-401.

18. Nonaka K, Kakikawa T, Sato A, et al. Efficacy and safety of sitagliptin monotherapy in Japanese patients with type 2 diabetes. Diabetes Res Clin Pract 2008;79:291-8.

19. Iwamoto $\mathrm{Y}$, Tajima N, Kadowaki T, et al. Efficacy and safety of sitagliptin monotherapy compared with voglibose in Japanese patients with type 2 diabetes: a randomized, double-blind trial. Diabetes Obes Metab 2010;12:613-22.

20. Cai X, Han X, Luo Y, et al. Efficacy of dipeptidyl-peptidase-4 inhibitors and impact on $\beta$-cell function in Asian and Caucasian type 2 diabetes mellitus patients: a meta-analysis. J Diabetes 2015;7:347-59.

21. Holst JJ, Deacon CF. Glucagon-like peptide 1 and inhibitors of dipeptidyl peptidase IV in the treatment of type 2 diabetes mellitus. Curr Opin Pharmacol 2004;4:589-96.

22. Holst JJ, Gromada J. Role of incretin hormones in the regulation of insulin secretion in diabetic and nondiabetic humans. Am J Physiol Endocrinol Metab 2004;287:E199-206.

23. Pospisilik JA, Martin J, Doty T, et al. Dipeptidyl peptidase IV inhibitor treatment stimulates beta-cell survival and islet neogenesis in streptozotocin-induced diabetic rats. Diabetes 2003;52:741-50.

24. Gerich J. DPP-4 inhibitors: what may be the clinical differentiators? Diabetes Res Clin Pract 2010;90:131-40.

25. Pratley RE, Schweizer A, Rosenstock J, et al. Robust improvements in fasting and prandial measures of beta-cell function with 
vildagliptin in drug-naïve patients: analysis of pooled vildagliptin monotherapy database. Diabetes, Obes Metab 2008;10:931-8.

26. Charbonnel B, Karasik A, Liu J, et al. Efficacy and safety of the dipeptidyl peptidase-4 inhibitor sitagliptin added to ongoing metformin therapy in patients with type 2 diabetes inadequately controlled with metformin alone. Diabetes Care 2006;29: 2638-43.

27. Aso Y, Fukushima M, Sagara M, et al. Sitagliptin, a DPP-4 inhibitor, alters the subsets of circulating CD4+ T cells in patients with type 2 diabetes. Diabetes Res Clin Pract 2015;110:250-6.

28. Kubota A, Maeda H, Kanamori A, et al. Pleiotropic effects of sitagliptin in the treatment of type 2 diabetes mellitus patients. $J$ Clin Med Res 2012;4:309-13.

29. Arjona Ferreira JC, Marre M, Barzilai N, et al. Efficacy and safety of sitagliptin versus glipizide in patients with type 2 diabetes and moderate-to-severe chronic renal insufficiency. Diabetes Care 2013;36:1067-73.

30. Aschner P, Kipnes MS, Lunceford JK, et al. Effect of the dipeptidy peptidase-4 inhibitor sitagliptin as monotherapy on glycemic control in patients with type 2 diabetes. Diabetes Care 2006;29:2632-7.

31. Seo C, Sakamoto M, Nishimura R, et al. Comparison of glycemic variability in patients with type 2 diabetes given sitagliptin or voglibose: a continuous glucose monitoring-based pilot study. Diabetes Technol Ther 2013;15:378-85.

32. Kubota Y, Miyamoto M, Takagi G, et al. The dipeptidyl peptidase-4 inhibitor sitagliptin improves vascular endothelial function in type 2 diabetes. J Korean Med Sci 2012;27:1364-70.

33. Fujitaka K, Otani H, Jo F, et al. Comparison of metabolic profile and adiponectin level with pioglitazone versus voglibose in patients with type-2 diabetes mellitus associated with metabolic syndrome. Endocr J 2011;58:425-32.

34. Fisman EZ, Tenenbaum A. Adiponectin: a manifold therapeutic target for metabolic syndrome, diabetes, and coronary disease? Cardiovasc Diabetol 2014;13:103.

35. Senmaru T, Fukui M, Kobayashi K, et al. Dipeptidyl-peptidase IV inhibitor is effective in patients with type 2 diabetes with high serum eicosapentaenoic acid concentrations. J Diabetes Investig 2012;3:498-502.

36. Inoue I, Shinoda Y, Nakano T, et al. Acarbose ameliorates atherogenecity of low-density lipoprotein in patients with impaired glucose tolerance. Metab Clin Exp 2006;55:946-52.

37. Vessby B, Gustafsson I-B, Tengblad S, et al. Desaturation and elongation of Fatty acids and insulin action. Ann N Y Acad Sci 2002;967:183-95.

38. Warensjö E, Rosell M, Hellenius M-L, et al. Associations between estimated fatty acid desaturase activities in serum lipids and adipose tissue in humans: links to obesity and insulin resistance. Lipids Health Dis 2009;8:37.

39. Kröger J, Schulze MB. Recent insights into the relation of $\Delta 5$ desaturase and $\Delta 6$ desaturase activity to the development of type 2 diabetes. Curr Opin Lipidol 2012;23:4-10.

40. Mayneris-Perxachs J, Guerendiain M, Castellote Al, et al. Plasma fatty acid composition, estimated desaturase activities, and their relation with the metabolic syndrome in a population at high risk of cardiovascular disease. Clin Nutr 2014;33:90-7.

41. Lu Y, Vaarhorst A, Merry AHH, et al. Markers of endogenous desaturase activity and risk of coronary heart disease in the CAREMA cohort study. PLOS ONE 2012;7:e41681. 